\title{
Design and Determination of Strength of Adhesive Bonded Joints
}

Tomáš Kalina, František Sedláček

Department of Machine Design, Faculty of Mechanical Engineering, University of West Bohemia, 30614 Pilsen. Czech Republic. E-mail: tkalina@rti.zcu.cz, fsedlace@rti.zcu.cz

The paper deals with methodology of prediction of adhesive bonded joints strength. Problematics of adhesive bonded joints is a very complex task. There are several different (different precision and different complexity) mathematical models of adhesive bonded joints, which attempts to describe the real behavior of adhesive and adhesive bonded joints during load as accurately as possible. This article presents a comprehensive overview of what to take into account and how to proceed with designing/controlling the strength of adhesive bonded joints. Mathematical models are supplemented by material data from experimental tests. The proposed methodology takes into account both adhesive and cohesive properties (material of bonded parts, surface treatment of bonded material, type of adhesive, thickness of adhesive, bonding technology, loading modes etc.). Methodology "how to proceed" is described in detail and is complemented with a flowchart.

Keywords: Adhesive Bond, Cohesive parameters, Epoxy Adhesive, Methodology, Surface treatment

\section{Introduction}

Adhesive bonded joints can be despised. For some people they may be untrustworthy as they considere them "weak" and can not replace conventional bonding method, such as welding, screw and rivet joints etc. However, not all materials can be welded, and for some materials adhesive bonding may be more advantageous than other bonding methods.

Adhesives have made great progress, high strength adhesives are produced. In some cases adhesive bonded joints may be stronger than bonded material. A typical example of this phenomenon may be polymeric materials. Especially for polymer fiber composite materials this is the most common bonding method. Composite materials are, more than other materials, prone to stress concentrators such as holes for bolts and rivets etc. [8], [9], [10]. Composite materials and thus also adhesive bonded joints are increasingly used in the aerospace industry and in sports and luxury cars. They have an important representation in these industries, for their strength, rigidity and weight ratio.

Though adhesive bonding may seem like a trivial mat- ter, it is not easy to describe precisely the material properties of the adhesive bonding and great caution and precision must be taken when making the bonding.

The content of this article is the presentation of methodology of prediction of adhesive bonded joints strength (composite materials with metals) when designing their design based on experimental tests and numerical simulations.

\section{Adhesive Bond}

The adhesive bonded joint is dismountable bond of the components (of the same or different materials) that is created by using the additional material - adhesive. Each bonded material has its own specific properties and therefore there do not exist universal adhesive (we understand it as a universal adhesive that would be suitable for all applications and materials). According to the bonded material a suitable adhesive is selected to make the joint quality, consistent and durable. The strength of adhesive bonded joints is depend for surface treatment of bonded material, which is carried out by means of different cleaners, chemical treatments or mechanical roughening.
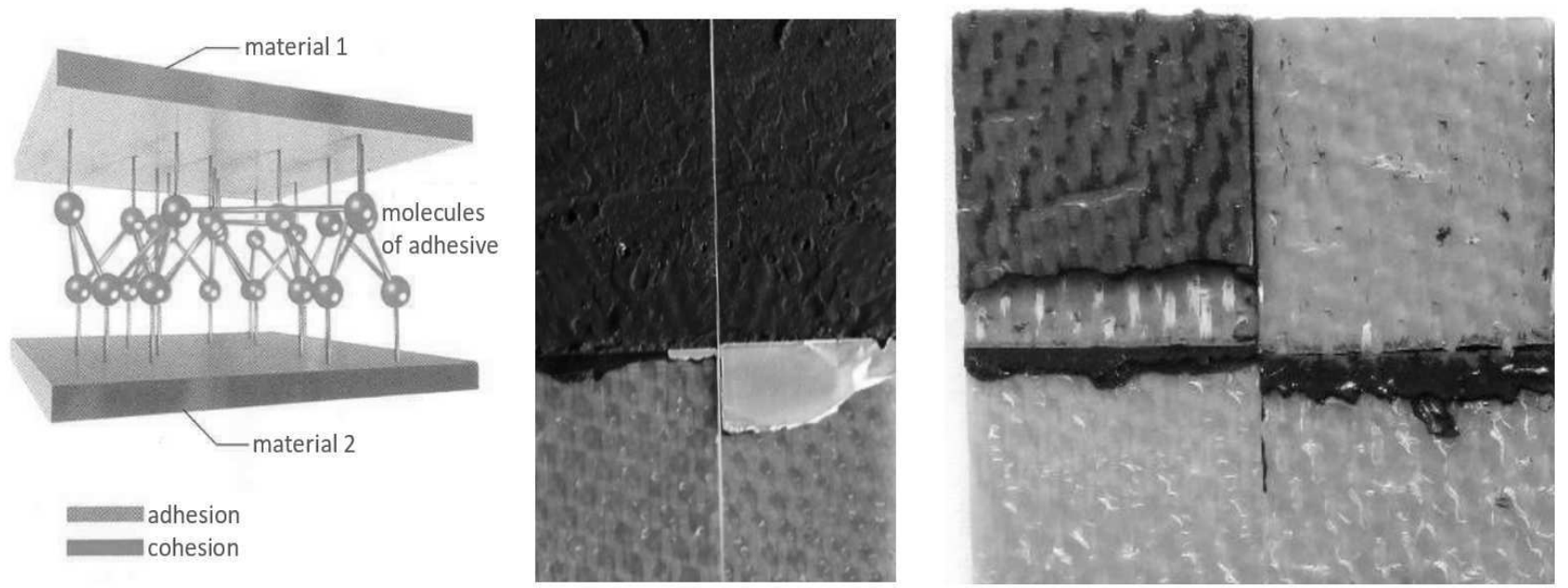

Fig. 1 a) Principle of a bonded joint [15]

b) Cohesive damage 
Adhesive bonded joint is based on interaction of adhesion and cohesion (see Fig. 1a)). The forces that ensure adhesiveness of bonded material and glue are called adhesion. Own coherence of cured adhesive is called cohesion. The advantages of adhesive bonds are that they have not Heat-affected zone (such as welding, [4], [5]) and they do not need to drill holes (stress concentrators) as bolted joints and riveted joints [6]. Figure 1b)-c) shown 2 modes of damage.

Adhesive bonded joints can be stressed by different modes of load. In general, adhesive bonded joints have high shear and pressure strength even under dynamic load. In case of low-cycle and high-cycle fatigue, adhesive bonded joints overcome weld joints. Conversely, adhesive bonded joints are less durable to peeling and bending load. It is therefore appropriate to modify the design
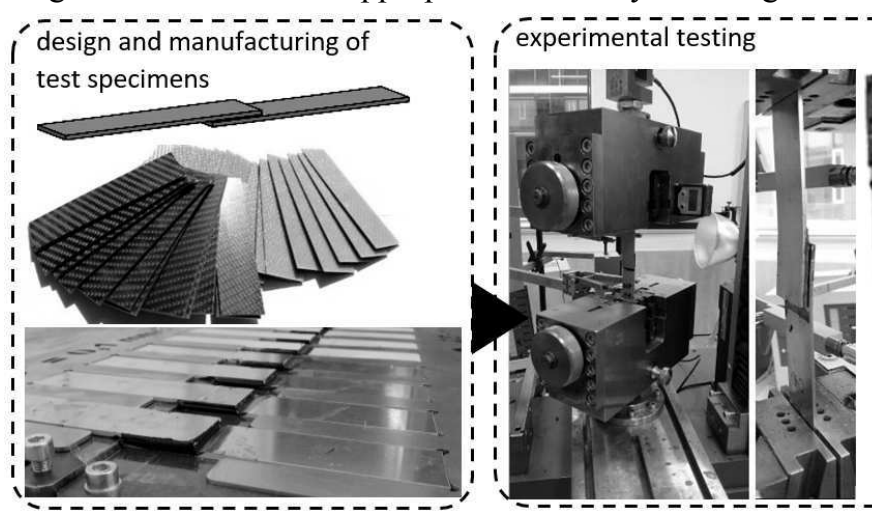

of bonded joints, so that the joint is loaded by shear (if it is possible).

\section{Adhesive properties}

The overall quality of the adhesive bond is influenced by many factors. To the most significant ones belong: the material of adhesive components, the surface treatment of adhesive areas, the quality of degreasing of adhesive areas. (These factors were examined [1]). Another, but no less important, factors are the type of adhesive, the thickness of adhesive layer, the technology of adhesion, etc. The paper [1] and diploma thesis [3] were focused on adhesion properties, specifically on influence material of adhesive components and the surface treatment of adhesive areas. Figure 2 shows a schematic representation a process obtaining adhesive parameters.

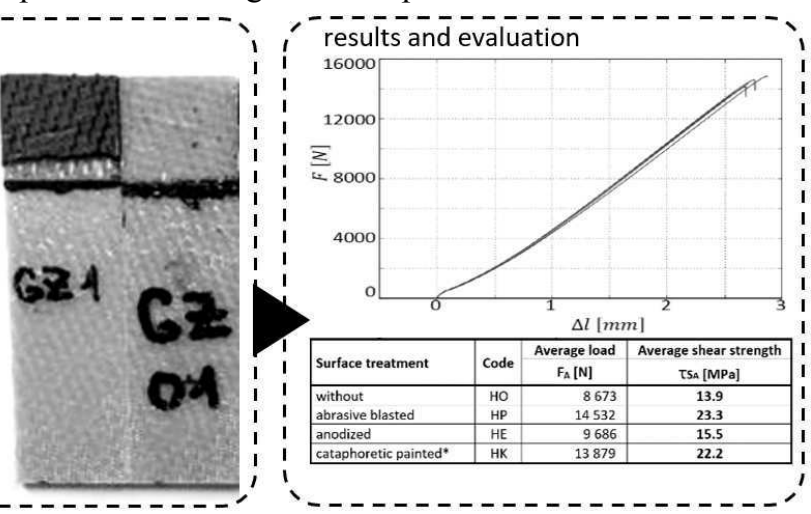

Fig. 2 Example of procedure for determining adhesive properties (for different materials)

\section{Cohesive properties}

There are three independent fracture modes, the crack opening mode (Mode I) is regarded as more important than the in-plane shear mode (Mode II) and out-plane shear mode (Mode III) because the Mode I fracture toughness is usually smaller than those of Mode II and Mode III and so the fracture is easily initiated and propagated under the Mode I loading condition. There is also a combination of these modes called 'Mixed-mode'. The individual modes of crack opening are shown in Figure 3. Particular cohesive models are given in [1], [2], [3], [11].
Figure 4 shows a schematic representation a process obtaining cohesive parameters.
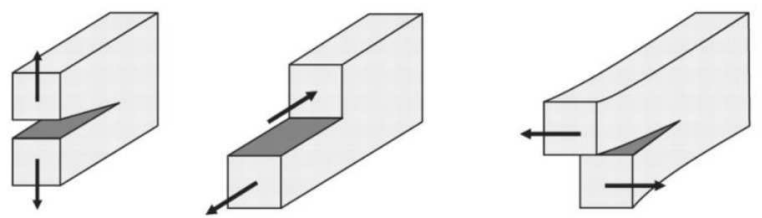

Fig. 3 The crack opening modes a) Mode I (opening); b) Mode II (in-plane shear); c) Mode III (out-plane shear)

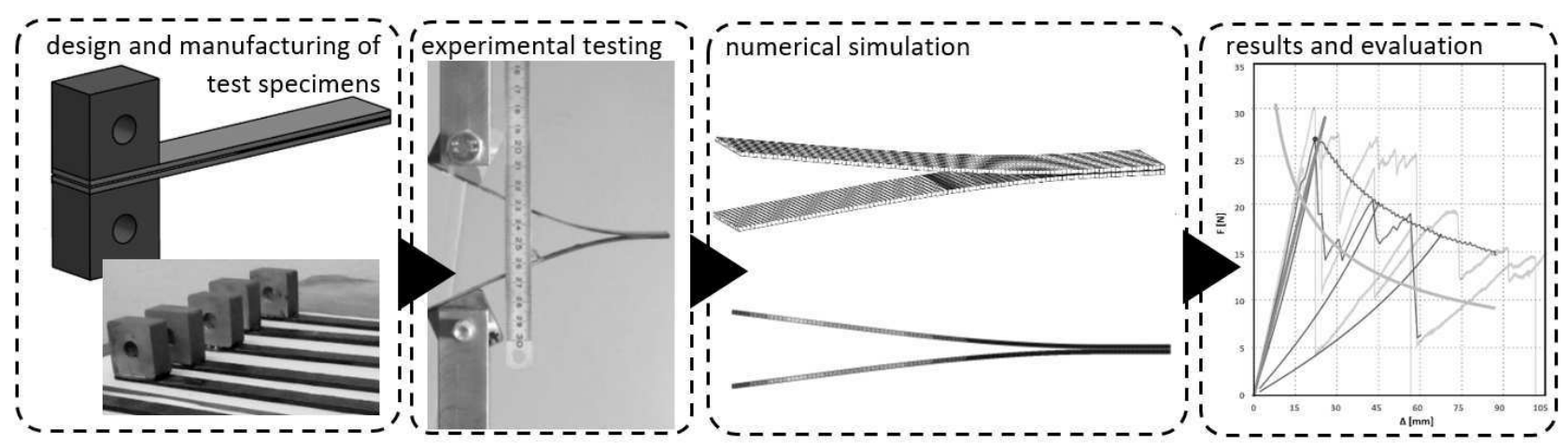

Fig. 4 Example of procedure for determining cohesive parameters (for Mode I-DCB test)

\section{Methodology of Prediction of Adhesive Bond Strength}

This methodology is based on the fact that the geometry and material of both bonded parts is usually an input for the adhesive bonded joint design. Figure 5 shows the detailed schematic representation of the methodology using a flowchart. First of all, it is always necessary to compile the detailed requirements specification according to the input data (in cooperation with the client). 
The next step in designing an adhesive bonded joint is to obtain the necessary mechanical properties of the bonded materials. (E, G, v etc.). Ideally, experimental measurements are performed. Several possible surface treatments can then be proposed. It is important to ensure good adhesion of the adhesive (adhesive properties), but also whether or not some degree of corrosion protection is required.

Based on the properties of bonded materials and specification of requirements, a suitable adhesive can be selected from datasheets (on the basis of recommendations by the manufacturer or on the basis of previous experience). All necessary parameters of the adhesive are not usually listed in the datasheet. Therefore, experimental testing is required to determine the mechanical properties of the adhesive. For the complete design/verification of the strength of the adhesive bonded joint, it is necessary to determine the cohesive and adhesive properties of the adhesive.

\section{Determination of strength in terms of cohesion}

Before determining the necessary cohesive properties of the adhesive, it is appropriate to determine how the part is loaded. (Mode I, II, III or mix mode). When we know the load mode, we select the corresponding standardized test(s). (for mode I it is DCB test according to ASTM D5528-01 [12], for mode II it is ENF test according to ASTM D7905 [13], etc. Often it is necessary to find at least all of 3 basic modes. A larger number of test specimens [7] must be produced for experimental testing. Experimental testing is mostly performed on a static materials testing machine.

From the experimental testing we usually get charts $\mathrm{F}-\Delta \mathrm{l}$. We process the measured data and filter out poor data (e.g. specimens for which cavities were found, etc.). But we need to determine the values $\mathrm{k}_{\mathrm{X}}$ and $\mathrm{G}_{\mathrm{XC}}$ for each mode of damage ( $\mathrm{kx}$ is the stiffness of adhesive layer; $\mathrm{G}_{\mathrm{XC}}$ is the critical value of the strain energy release for Mode X). One way to get the required parameters is to create a numerical simulation (with cohesive elements / with cohesive contact), which coincides with the experiment and after several iterations (by changing the input simulation data) to achieve the conformity of numerical simulation and experimental tests (chart overlay). If we get a good conformity between charts, we get the necessary parameters from the numerical simulation for the tested mode. We repeat this procedure for all 3 basic modes of damage. The detailed procedure is given in articles [2], [3], [11]. We get usually k $\mathrm{k}_{\mathrm{I}}, \mathrm{k}_{\mathrm{II}}, \mathrm{k}_{\mathrm{III}}, \mathrm{G}_{\mathrm{IC}}, \mathrm{G}_{\mathrm{IIC}}, \mathrm{G}_{\mathrm{IIIC}}$, or their ratio in the case of mixed mode (depends on load mode).

The obtained parameters generally characterize the properties of the adhesive and can therefore serve as an input (the material properties of the adhesive) for any shape of the glued parts (using this particular adhesive). In the next step, a numerical simulation (a transient task using cohesive elements or cohesive contact) of a real part has already been compiled. The numerical model includes material data of bonded materials and all obtained cohesive parameters. Loading force is applied gradually in small increments. (Once the maximum force has been reached, it is possible to relieve the force gradually back to $0 \mathrm{~N}$ and eventually examine permanent damage). In this type of task we do not compare the stress, but socalled Cohesive damage is compared. Cohesive damage is a coefficient that becomes $<0-1$ ). If a cohesive damage to achieve value 1 , respectively, when it approaches very close to 1 , it is likely that the material will be damaged at a given load. In this simulation, it is possible to continue over the first damage and examine how the bond will continue to behave.

If the adhesive bonded joint fails, there is a possibility to go back to the choice of adhesive where a stronger adhesive can be chosen or other input values can be adjusted (in agreement with the client). In the event that the bond will pass, we may be interested in the fact whether this bonded joint is oversized. For example, whether a smaller bonded area would be enough, or whether to use less firm (cheaper) adhesive, with both options leading to financial savings. If an adhesive bonded joint is satisfied and no further optimization is required, the next step may be taken.

\section{Determination of strength in terms of adhesion}

Adhesion properties often result in greater simplification. There is not a trivial model to include the influence of surface roughness on the simulation. We therefore measure shear strength on lap-joint specimens for different materials and different surface treatments. These strengths can be compared with each other. The specimens and the testing is performed according to standard ASTM D5868 [14].

On the basis of determined properties, we can recommend a suitable surface treatment at a given load or, on the contrary, with a given material and surface treatment, we can determine maximum adhesion strength. If none of the proposed surface treatments is suitable, there is the possibility to return back to designing the surface treatments and suggest another one that was not considered for the first time, because of technical or financial difficulty. The second option is to return to the input values and to optimize geometry (e.g., to enlarge the bonded area) or to change the material of the bonded parts, or to change the adhesive and process completely or partially repeat.

\section{Experimental verification on a real part(s)}

It is advisable to verify the results on the real part(s) and to make a comparison of the calculated and measured values. If the test part fails, it is possible to return back and there are several options: change of the selected adhesive, change of the surface treatment, change of the geometry to change the load mode, etc. ). If the experimental verification is successful, the final solution has been reached and the manufacturing documentation for the parts can be processed. However, if the part fails, it is useful to know how and why the model differs from the real part. It is appropriate to determine whether there is an error, or any great simplification. 


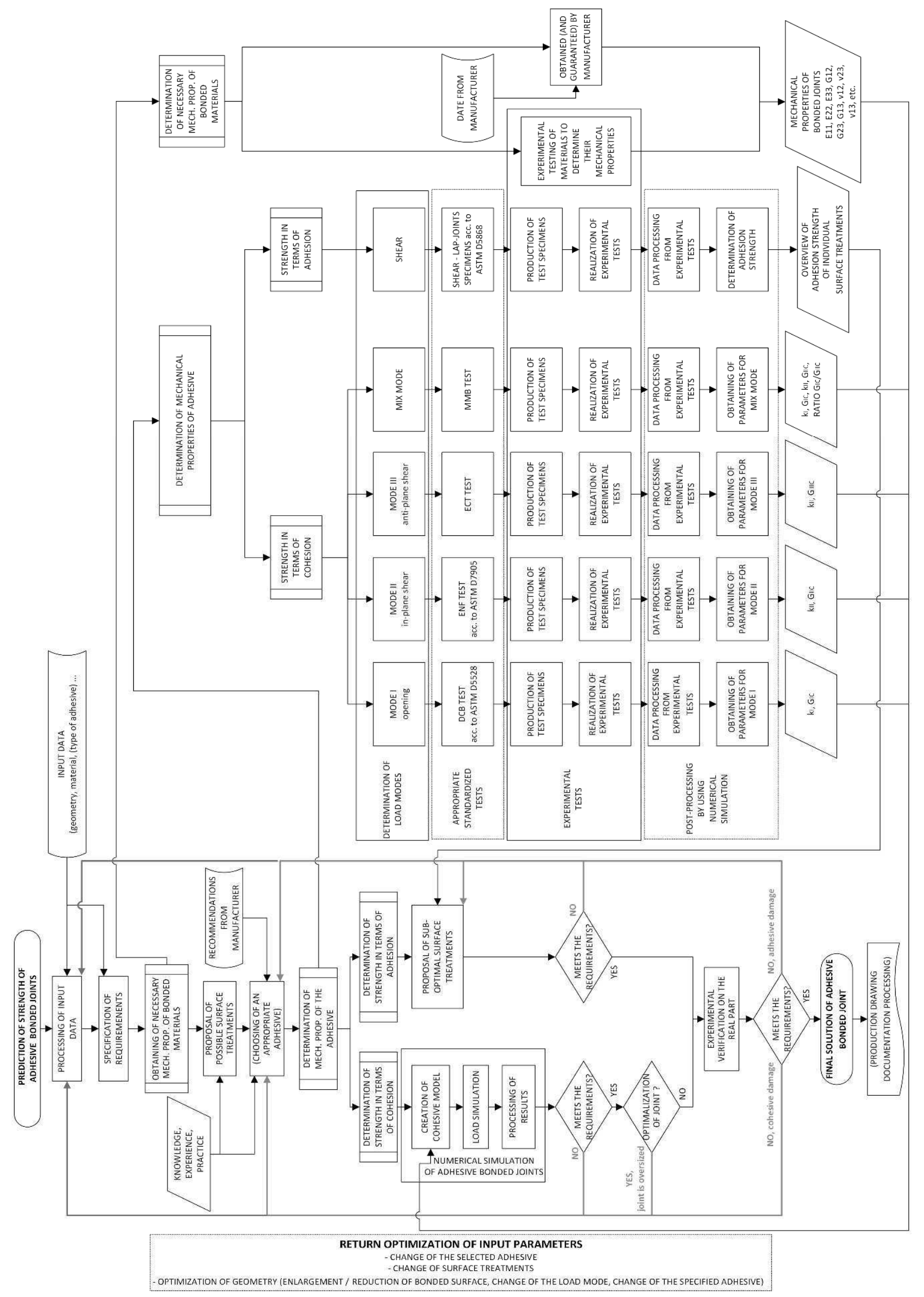

Fig. 5 Flowchart - Methodology of prediction of adhesive bonded joints strength 


\section{Conclusion}

The outcome of this paper is a description of the methodology of prediction of adhesive bonded joints strength in the design of their structure. This methodology has been formed and developed during practical applications for a long time. The proposed methodology deals in detail with the proposing/checking of adhesive bonded joints, from the analysis and specification of requirements through the selection of adhesive, the surface treatments of bonded materials and the determination of the cohesive parameters of the adhesive to the complex evaluation of the adhesive bonded joint.

To determine the parameters of the adhesive properties it is necessary to perform experimental tests and their statistical evaluation. In order to obtain cohesive parameters, mathematical models need to be supplemented with mechanical properties of bonded materials and adhesives, that is achieved by experimental tests and numerical simulations.

The proposed methodology is universally described and can be applied to any adhesive bonded joint. The methodology has been successfully applied to a few practical examples in designing the Formula student car as well as in partnership with automotive industry partners.

\section{Acknowledgement}

This paper is based on work sponsored by project SGS2019-001 (The complex support of designing of technical equipment IV).

\section{References}

[1] KALINA, T.; SEDLACEK, F.; KRYSTEK, J. (2018). Determination of the influence of adherent surface on the adhesive bond strength. MATEC Web of Conferences, Vol.157, 14 March 2018, Article number 05012, ISSN: 2261236X, DOI: $10.1051 /$ matecconf $/ 201815705012$

[2] KALINA, T.; SEDLACEK, F.; KROUPA T. (2018). Determination of cohesive parameters for mode I of epoxy adhesive. Proceedings of the 29th DAAAM International Symposium, pp.0746-0751, B. Katalinic (Ed.), Published by DAAAM International, ISBN 978-3-902734-20-4, ISSN 17269679, Vienna, Austria, DOI:10.2507/29th.daaam.proceedings. 108

[3] KALINA T. (2017) Designing of bonded joints composite materials, Diploma thesis, Department of Machine Design, University of West Bohemia, Pilsen, Czech Republic

[4] KALINA, T.; HELLER, P.; CHVAL, Z.; SEDLÁČEK, F.; KŘÍŽEK M.; BARTOŇ L. (2018) Numerical Simulation and Experimental Testing of Two-axle Chassis of Low-floor Trams. Manufacturing Technology, pp.248-254, Vol.18, No.2. UJEP, 2018, ISSN: 1213-2489.
[5] ŠPIRK S. (2017). The Collision of Unbelted Passenger with Assessment of Various Vehicle Interior, In: Manufacturing technology: journal for science, research and production. - ISSN 12132489. - Vol. 17, No. 6 (2017), pp. 962-969, No. of acticle: M2017187.

[6] RAZ, K., HORA, J., PAVLATA, P. (2017) Unconventional Materials Usage in Design of Vehicle Bodies In: Manufacturing technology: journal for science, research and production. - ISSN 1213-2489. - Vol. 17, No. 5 (2017), pp. 823-827, No. of acticle: MT2017150.

[7] JENICEK, S., VRATISLAV, K., KALINA, T., MASEK, B. (2016) Use of waterjet in manufacturing test bars of high-strength steels, In: Annals of $D A A A M$ and Proceedings of the International DAAAM Symposium, 27 (1), pp. 219-224. doi: 10.2507/27th.daaam.proceedings.032

[8] MARKOVICOVA, L., HURTALOVA, L., ZATKALIKOVA, V., GARBACZ, T. (2014). Evaluation of composite structures by light microscopy and image analysis, Manufacturing Technology, ISSN:1213-2489, 14 (3), pp. 351355.

[9] MARKOVICOVA, L., ZATKALIKOVA, V. (2016). Composite Materials Based on pa Reinforced Glass, Fibers, In: Materials Today: Proceedings, Vol. 3, pp. 1056-1059, E-ISSN:2214-7853

[10] CHUNG \& DEBORAH, D. L. (2003) Composite materials: functional materials for modern technologies. London: Springer. 289 pp. ISBN $185233665 \mathrm{x}$

[11] SKOVAJSA, M. \& SEDLACEK, F. (2017) Numerical simulation of delamination in laminated composite plates using cohesive elements, $27 \mathrm{TH}$ DAAAM International symposium DOI:10.2507.

[12] Standard Test Method for Mode I Interlaminar Fracture Toughness of Unidirectional Fiber Reinforced Polymer Matrix Composites, Designation: D 5528-01 (Reapproved 2007)

[13] Standard Test Method for Determination of the Mode II Interlaminar Fracture Toughness of Unidirectional Fiber-Reinforced Polymer Matrix Composites, Designation: D7905/D7905M

[14] Standard Test Method for Lap Shear Adhesion for Fiber Reinforced Plastic Bonding, Designation: D5868-01

[15] Collective of authors, Loctite - Worlwide Design Handbook. Mainz: Erasmusdruck GmbH. 452. ISBN 0-9645590-0-5 (1998) 